\title{
Arbolado urbano, higienismo y redes de conocimiento en Canarias
}

\section{Mari Carmen Naranjo Santana}

\section{(2) OpenEdition}

1 Journals

Edición electrónica

URL: https://journals.openedition.org/cher/558

DOI: $10.4000 /$ cher.558

ISSN: 2803-5992

\section{Editor}

Presses universitaires de Strasbourg

\section{Edición impresa}

Fecha de publicación: 10 junio 2021

Paginación: 175-205

ISBN: 9791034400928

ISSN: 1968-035X

\section{Referencia electrónica}

Mari Carmen Naranjo Santana, «Arbolado urbano, higienismo y redes de conocimiento en Canarias», reCHERches [En línea], 26 | 2021, Publicado el 15 septiembre 2021, consultado el 19 noviembre 2021 URL: http://journals.openedition.org/cher/558 ; DOI: https://doi.org/10.4000/cher.558 


\title{
Arbolado urbano, higienismo y redes de conocimiento en Canarias
}

\author{
Mari Carmen Naranjo Santana*
}

... y su tronco gritó: ¿por qué me quiebras? ... ¿por qué desgarras? ¿no tiene tu espíritu piedad alguna?/

Hombres fuimos y ahora nos han hecho plantas:

bien debería ser más piadosa tu alma aunque fuéramos de sierpes almas (La Divina Comedia, Infierno, canto XIII. Dante Alighieri)

\section{Introducción y desarrollo urbano de Santa Cruz de Tenerife y de Las Palmas de Gran Canaria}

En Europa, desde finales del siglo xvini y a lo largo de todo el siglo XIX, la influencia que el entorno ambiental y el medio social suponían en el desarrollo de las enfermedades fue adquiriendo importancia, poniendo el foco de atención en la falta de salubridad de las ciudades y en las condiciones de vida y de trabajo en ellas. Se otorgó una especial atención a los vientos como agentes dispersores de los miasmas, a lo que se unió la idea de tratar la enfermedad de manera fusionada entre la medicina y lo social, prestando atención a factores como la pobreza, la mala alimentación, el hacinamiento en los barrios, etc.

Los «decorados» vegetales de la Ilustración y las prácticas higienistas plantearon una nueva forma de planificar las ciudades, en la que las alineaciones arbóreas formarían parte de las nuevas calles, de las avenidas y de las grandes zonas verdes para uso público (Reguera 1992: 109-110). Dos serían los grandes pilares que dieron paso a este nuevo esquema verde: la ciudad y la belleza que

* Mari Carmen Naranjo Santana, Investigadora independiente. ORCID: 0000-0002-37639102,<mcnaranjosan@gmail.com>. 
el arbolado le otorgaba, como muestra de racionalidad y de prestigio político, social y económico; y los espacios verdes, como núcleos higiénicos en el mundo obrero (atraían la lluvia, saneaban la atmósfera, ambientaban espacios para la moralidad...), aunque la intervención higiénica en torno a lo industrial, tal y como han señalado Rodríguez Ocaña y Martínez Navarro, fue más asistencial que real porque la industria preocupaba dado que generaba molestias urbanas pero, en términos generales, no se actuaba en el interior de las fábricas sino fuera de ellas (Rodríguez y Martínez 2008: 42-43).

En España, aunque desde mediados del siglo xviıI y con la llegada de textos y publicaciones sobre el diagnóstico y el tratamiento de las enfermedades, médicos como Francisco López de Arévalo, Josep Masdevall y Ambrosio M. Jiménez de Lorite se ocuparon de la problemática de la higiene, no fue hasta los primeros años del siglo xıx cuando en el país se desarrolló el higienismo como doctrina de base científica, acorde con las noticias del ideario de la Revolución francesa y el hito de la Constitución española de 1812, que calaron en la nueva burguesía con ansias de cambio (Alcaide 1999: 32-54). En este marco, la vegetación se convirtió en una gran aliada por su eficiencia para resolver o atenuar el deterioro ambiental que se estaba dando en las ciudades, saliendo de los espacios privados para conquistar lo público.

La Ilustración, tal y como ha señalado M. Rosario del Caz (Del Caz 2018: 8), supuso un punto de inflexión en la generalización de la plantación de arbolado en el país porque, bajo la protección real de Carlos III, las Sociedades Económicas de Amigos del País, que se crearon con el fin de difundir los conocimientos científicos y técnicos, tenían entre sus diversas preocupaciones el avance de la agricultura (la veían como requisito previo e indispensable para la revolución industrial) y, junto a ella, al arbolado. Esto se daba en una sociedad que, a medida que transcurrió el siglo, se polarizó entre quienes tenían una opinión favorable de las repoblaciones forestales y aquellos que se mostraban contrarios, hasta que, a partir de la segunda mitad del siglo XIX, coincidiendo con la designación del urbanismo como nueva disciplina, la cuestión arbórea se trasladó a la ciudad demandando parques públicos en las ciudades y comenzando las corporaciones municipales a dotar el interior de los cascos urbanos de zonas verdes públicas, tras la demolición de los conventos desamortizados.

Esta sería, también, la centuria en la que surgió la construcción urbanística del ensanche ${ }^{1}$, como respuesta a la necesidad de ampliar la ciudad extramuros, y el siglo que vio nacer el modelo de ciudad jardín, con el que se pretendía aliviar la industrialización con una mezcla entre ciudad y campo.

1 El más conocido es el caso del Eixample en Barcelona, impulsado por Ildefons Cerdà en 1860, ante la necesidad de limpiar las calles y las casas de las infecciones y de las malas ventilaciones. Con él se desarrolló la estructura en cuadrícula y el corte de las avenidas cruzadas en diagonal, dando un papel clave a los parques y a los jardines en el interior de las manzanas. 
En el caso concreto de Canarias, la ciudad de Santa Cruz de Tenerife sufrió su verdadero desarrollo poblacional y urbanístico en el siglo XviII, vinculado al progreso del puerto, aunque fue en 1803 cuando se le otorgó el derecho a establecer su propio ayuntamiento y a emanciparse administrativamente del municipio de La Laguna. La ciudad contaba con una muralla, numerosas fortificaciones y, entre sus plazas o espacios públicos, sobresalían el entorno del Palacio de la Capitanía General de Canarias, la actual plaza de la Candelaria (se remonta al siglo xvi como patio de armas del desaparecido Castillo de San Cristóbal, pero no aparecería como espacio público hasta el siglo XVIII) y la alameda de la Marina (también conocida como la alameda del Muelle, data de finales del siglo xviII, siendo frecuentada por la alta sociedad santacrucera).

Las Palmas de Gran Canaria, por su parte, quedó definida desde su fundación por la plaza Mayor de Santa Ana, en la que se ubicaba una clara representación social, institucional y política al concentrarse en ella algunas viviendas e importantes edificios como la Catedral de Santa Ana, el Palacio del Obispo y las Casas Consistoriales. La ciudad estaba limitada por dos murallas, de norte y de sur, que la protegían de las invasiones piráticas, pero, durante el ochocientos, la pérdida de esa función defensiva, la influencia de la corriente higienista y los intereses de la burguesía de comunicar la ciudad histórica con el naciente puerto de la Isleta, provocaron el derribo de la muralla norte, el crecimiento lineal de la población y el asentamiento de las clases sociales menos pudientes en viviendas hacinadas en las laderas de las montañas que rodeaban la urbe, dando lugar al sector territorial que se conoce comúnmente como Los Riscos.

\section{Primeras actuaciones de arbolado en Las Palmas de Gran Canaria}

Aunque desde 1791 la ciudad de Las Palmas contó, como era común en otras ciudades europeas, con la Alameda Antigua (situada en un pequeño solar donde hoy se encuentra el parque de San Telmo), no fue hasta la segunda mitad del siglo xIX cuando esta población sufrió un impulso en cuanto a su vegetación.

En la primera mitad de siglo, el arbolado de la urbe era deficiente, ciñéndose a intervenciones puntuales como el paseo que, a propuesta del compositor Benito Lentini (1793-1846), se inició, en 1840, en el margen del barranco Guiniguada, popularmente conocido como La Plazuela, y que fue objeto de numerosas críticas por su estado de abandono. Dos años más tarde (aunque sus obras llegaron hasta 1866) se inauguró la alameda, conocida a partir de 1892, y hasta la fecha, como alameda de Colón, que ocupó un lugar del extinguido convento de Santa Clara y cuya organización del espacio en varias avenidas estaba pensado para hacer una clara distinción social, reservando las vías centrales a las clases sociales mejor posicionadas, sirviendo como jardín-paseo y destacando en él los plátanos del Líbano y los laureles de indias (Bosch 1967: 72). En el otro extremo de la alameda, la plaza del Teatro, hoy de Cairasco, hermoseada por su fuente y sus palmeras y coronada por el primer coliseo de la ciudad. Como vía central 
de la ciudad, la calle Mayor de Triana, que, desde 1849, fue objeto de un plan de embellecimiento con palmeras (Quesada 1992: 1519).

En paralelo a estas intervenciones, pero en el ámbito nacional, empezaba a difundirse la obra de importantes médicos españoles como Mateo Seoane Sobral y sus discípulos Pedro Felipe Monlau y Francisco Méndez Álvaro. La labor de estos profesionales y la creación, desde 1847, de la primera Dirección General de Sanidad y la posterior Ley del Servicio General de Sanidad (1855) fueron especialmente relevantes en el avance de la salud pública en el país y el higienismo, poco a poco, se fue implantando como paradigma médico.

En las Islas, a comienzos de la segunda mitad del siglo XIX, aún no había calado la importancia higiénica del arbolado, pero sí se había consolidado en el debate público la reclamación de su necesidad como ornato, en un contexto de avance urbanístico impulsado, entre otros, por las desamortizaciones y el floreciente cultivo y la exportación de la cochinilla. En Las Palmas de Gran Canaria, la prensa se convirtió en el órgano de control de la comisión del Ayuntamiento encargada de los plantíos. El diario El Canario, por ejemplo, alababa la labor municipal por los álamos y tarahales que había plantado en las montañas, al oeste de la ciudad, en la izquierda del barranco Guiniguada, y por el gran número de higueras en la parte sur. Pero, a su vez, también sugería que plantasen palmeras y lentiscos porque, aunque crecían lento, darían paso a un bello panorama que ocasionaría que los hijos de los coetáneos

$[\ldots]$ nos deberian $[s i c]$ tan dulce recuerdo y agradecerian $[$ sic] esto, tanto como nosotros culpamos à $[$ sic $]$ nuestros progenitores por el destrozo que causaron en nuestros antiguamente verdes y frondosos montes, hoy áridos y despoblados [...] (El Canario 11/01/1855: 1-2).

Pero la prensa también actuó de sector crítico, como fue el caso de El Ómnibus (1855-1868), que cuestionó la elección de palmeras para la plaza de Santa Ana porque era un árbol que tardaba en crecer, no hacía más habitable el espacio público porque no daba sombra y, si se perdían, no eran reemplazables por otras de idéntico tamaño, por lo que apostaban por la plantación de árboles que en dos años hubieran hecho de la plaza un paseo agradable (El Ómnibus 07/02/1857: 1). Tres años más tarde, el mismo diario sugería a la comisión municipal que, siguiendo los pasos de la ciudad vecina de Santa Cruz, aclimatase la Ficus religiosa en la Alameda, en las plazas y en los paseos públicos (El Ómnibus 28/01/1860: 2); criticaba el estado del arbolado de las plazas de Santa Ana y San Bernardo, en comparación con los naranjeros que embellecían las plazas principales de la ciudad tinerfeña (El Ómnibus 23/01/1861: 1-2); y proponía que se quitasen las palmeras que se habían plantado en la plaza del Teatro porque no cumplían la función de embellecer y dar sombra, además de que obstaculizaban la entrada y salida al coliseo (El Ómnibus 31/08/1861: 2). No obstante, no solo el núcleo urbano fue motivo de observación por la prensa, sino que la vegetación de las montañas que rodeaban la ciudad también fue tratada, apercibiendo que 
las montañas de San Francisco, San Lázaro y San Juan se dotasen de verde (El País 07/02/1865: 1-2), una ausencia que en Los Riscos se convirtió en constante ${ }^{2}$.

Los avances en las doctrinas higienistas comenzaban a proliferar en el archipiélago canario y el tratamiento del arbolado como mero ornamento empezaba a cambiar, para pasar también a tratarlo como objeto de estudio y desarrollo económico. De ahí que la prensa planteara que, en el supuesto de que fuese necesaria una escuela de agricultura en las Islas, esta se ubicase en la ciudad, no solo porque tenía el mayor número de población de la provincia, sino también porque en esa localidad abundaba el agua para facilitar los ensayos en la parte práctica de la formación, por la benignidad y variedad de su clima, por disponer de terrenos para la aplicación de los conocimientos adquiridos y por la existencia de norias y estanques (El Ómnibus 24/01/1863: 2).

La Sociedad Económica de Amigos del País de Las Palmas de Gran Canaria (en adelante, SEAPGC) también se sumó a las propuestas de mejora del arbolado público recomendando, por ejemplo, la plantación de laureles de indias en aquellos parajes donde era incómoda la plantación de árboles frutales, al ser excelentes para adornar los paseos por su verdor y hermoso ramaje, y visto el resultado en zonas como La Alameda, la plaza de la Catedral y el paseo del Castillo de Casa Mata (Boletín de la Sociedad Económica de Amigos del País de Las Palmas de Gran Canaria -en adelante BSEGC- 31/10/1864: 8).

Pero si hubo un proyecto por el que apostó la SEAPGC fue por los intentos de dotar a la ciudad de Las Palmas de un jardín de aclimatación (iniciativa que se ampliaría posteriormente con la idea de crear, junto al jardín, una escuela práctica de agricultura). Esta propuesta no es de extrañar si se tienen en cuenta los avances científicos vinculados a la botánica, con importantes expediciones enfocadas al estudio de la flora de la América hispana y la introducción de especies exóticas. A lo que se sumaban el interés que las particularidades físicas de Canarias despertaban en el continente europeo; la experiencia, desde el siglo XVIII, de la puesta en marcha del Jardín de aclimatación de La Orotava (Tenerife); y, como hemos señalado, el interés que el espacio arbóreo y vegetal habían ido despertando en diferentes ámbitos.

La propuesta de instalación del jardín de aclimatación en Las Palmas de Gran Canaria fue cursada (1864) a la SEAPGC por dos de sus socios: Domingo José Navarro Pastrana y Domingo Déniz Greck.

El primero, Navarro, obtuvo la licenciatura de medicina en 1835 en Barcelona, ciudad en la que desarrolló labores de ayuda sanitaria en la epidemia de cólera (experiencia que le sirvió, años más tarde, en Gran Canaria, para hacer frente también a la epidemia de cólera que azotó a la isla) y en la que vivió una

2 Y ello, a pesar de que un mandato de 1866 establecía la concesión de solares con la condición de plantar dos, o más árboles, junto a la nueva construcción. Pero la prescripción no pasó de su mención, porque el Ayuntamiento descargó en los particulares la responsabilidad de su cumplimiento (Quesada 1992: 1523). 
época en la que el florecimiento industrial era imparable, especialmente en el ramo textil ${ }^{3}$.

Déniz Greck, por su parte, se formó en medicina en Montpellier, ciudad que también se desarrolló industrialmente hasta convertirse en un importante centro de la región. Una vez establecido en Gran Canaria, impartió clases en el Colegio de San Agustín y también se distinguió en la lucha contra la epidemia del cólera morbo de 1851, además de ser pionero en el cultivo de la cochinilla y de interesarse por el fomento de la agricultura en general ${ }^{4}$.

Dadas las formaciones, perfiles e intereses de ambos próceres, no debe extrañarnos que la iniciativa de instalación del jardín de aclimatación partiera de ellos y así, en carta fechada a 28 de mayo de 1864, se dirigieron a la Económica para que solicitase al Gobierno la instalación del jardín en la ciudad, argumentando que su terreno, clima y la abundancia de aguas favorecían la vegetación, y por «[...] las ventajas que han de obtener estas islas en la aclimatacion [sic] de muchas especies de árboles originarios de África y América [...]» (BSEGC 30/06/1864: 5). No obstante, y a pesar del intento, tuvieron que transcurrir varios años para que aquella propuesta se retomara con fuerza, porque no fue hasta 1866 cuando la prensa se hizo eco de la importancia de la aclimatación de las plantas y de la creación de un jardín de plantas intertropicales (de Asia, África y América) en la ciudad de Las Palmas (Naranjo 2016: 380).

Por aquel año de 1866, la Alameda también empezaba a dotarse de sombra gracias a los plátanos del Líbano que se habían plantado en los años cuarenta, pero Déniz Greck soñaba con hacer de aquel espacio un paseo burgués, al estilo del que había disfrutado durante su formación en Montpellier en el paseo o plaza de Peyrou. Esta quimera, anclada en los recuerdos de juventud, se hizo realidad cuando el alcalde, López Botas, propuso a Déniz la dirección de la Alameda. El médico aceptó la propuesta y entró en funciones el 8 de agosto de 1866, con el propósito de que los vecinos gozaran de aquel espacio

[...] como un «salón» al aire libre, en el que era preciso guardar las más exquisitas normas de urbanidad, como si se encontraran en una elegante estancia, adornada de cornucopias y alfombras [...] (Alzola 2008: 81-95).

Para la repoblación de las plantas, Déniz se puso en contacto con el jardinero y botánico suizo Hermann Wildpret, responsable, desde 1860, del Jardín

3 En Gran Canaria, fue profesor del Colegio de San Agustín en las asignaturas de Historia Natural y Fisiología e Higiene; temáticas que trató a lo largo de toda su vida, no solo por el ejercicio de su profesión, sino también por su pertenencia a colectivos como el Gabinete Literario y la Sociedad cultural y científica El Museo Canario, de la que fue presidente.

4 Miembro de colectivos como la mencionada Sociedad Económica y el Gabinete Literario, ocupó numerosos cargos en materia de sanidad e higiene en la Isla, como vocal de la Junta Municipal de Sanidad y Médico de Visitas de Naves, vocal de la Junta Provincial de Beneficencia y Director del Hospital de San Martín, Subdelegado de Medicina y Director de Jardines Públicos, entre otros. 
de Aclimatación de La Orotava ${ }^{5}$. Hasta que, con el paso del tiempo y no sin dificultades económicas, porque solo contaba con el apoyo del Ayuntamiento y con algunas suscripciones públicas para mejoras puntuales, Domingo Déniz hizo de la Alameda un vergel que llegó a tener su propio reglamento de urbanidad, de riegos y reserva de agua (Alzola 2008: 81-95). La Alameda ocupó sus desvelos hasta el día de su muerte, pero su proyección de arbolado urbano no se ciñó exclusivamente a esta, sino que se extendió a otros espacios como la plaza del Teatro, para la que presentó en 1867 un informe a la comisión de ornato del Ayuntamiento proponiendo su mejora.

Por aquella fecha, se produjeron otras iniciativas en materia de arbolado, como la oferta de la Sociedad Económica de Santa Cruz de Tenerife de vender semillas de Eucaliptus globulus a la isla de Gran Canaria para ponerlos en alamedas, paseos, plazas y otros terrenos públicos (El Ómnibus 12/02/1868: 2), o la propuesta de la Económica de Gran Canaria al Ayuntamiento de la ciudad de eliminar las arenas del istmo, roturar el terreno y urbanizar desde el Puerto de La Luz hasta la punta de Guanarteme, rodeando la zona de árboles frutales y de adorno para convertir el istmo en una «vega productora» (BSEGC 30/09/1868: 16).

Además, también se retomó la propuesta de crear el jardín de aclimatación, a raíz de que la Junta Superior de Gobierno de Gran Canaria se pronunció para instruir el derribo del edificio que había servido como monasterio de las religiosas de San Ildefonso en Vegueta, con el propósito de ceder el terreno al Ayuntamiento para que procediese a su derribo y construyera en el solar el citado jardín y una escuela de agricultura ${ }^{6}$. La propuesta, que, como hemos adelantado, fue liderada por la SEAPGC a raíz de la idea de sus socios Navarro y Déniz, contó también con el apoyo de particulares como Juan Massieu y Westerling y el artista Manuel Ponce de León y Falcón, que presentaron a la citada Junta un informe, de 20 de octubre de 1868, en el que proponían el diseño del edificio destinado a jardín, escuela práctica de agricultura y gabinete de historia natural, basándose en la escasez de vegetación de la ciudad, tanto en sus plazas como en sus paseos, así como su estado de abandono agrícola ${ }^{7}$. Finalmente, el derribo del solar se ejecutó por el Ayuntamiento, pero no se llevó a cabo ni la propuesta de jardín y escuela de Massieu y Ponce de León, ni otro proyecto que la institución municipal encargó con igual propósito a Francisco de la Torre.

5 Diseñador, también, del jardín de la Rambla de Ravenet, en Santa Cruz de Tenerife (1861), y del jardín del Gran Hotel Santa Catalina (1899), entre otros (Tous 2015: 399).

6 AHPLP, Ayuntamiento de Las Palmas, Sección Obras públicas (1831-1930), n. inv. 21, leg. 7, expdte. 102, Expediente sobre concesion del monasterio de San Ildefonso al Excmo. Ayuntamiento de esta Ciudad y derribo del mismo edificio para enaltecer un jardin botanico, 1868-1875, f. 1r.-3v.

7 AHPLP, Ayuntamiento de Las Palmas, Sección Obras públicas (1831-1930), n. inv. 21, leg. 7, expdte. 102, Expediente sobre concesion del monasterio de San Ildefonso al Excmo. Ayuntamiento de esta Ciudad y derribo del mismo edificio para enaltecer un jardin botanico, $1868-1875$, f. $6 \mathrm{r} .-14 \mathrm{v}$. 


\section{La Junta mixta y permanente de arbolado}

Hasta comienzos de los años setenta del siglo XIX, como hemos visto, lo concerniente a arbolado siempre estuvo bajo la tutela de la corporación municipal, pero contó con el seguimiento de la prensa, de profesionales y con el apoyo de colectivos de la sociedad civil como la SEAPGC. Fue precisamente en el seno de esta sociedad, y especialmente en las redes de colaboración y de conocimiento que se daban entre sus socios, donde nació la idea de crear la primera Junta mixta de arbolado urbano. Entre los documentos que custodia el Archivo Histórico Provincial de Las Palmas se conserva un expediente de $1871^{8}$, que se abre con una misiva de la SEAPGC (por aquellas fechas dirigida por el médico Manuel González y González que, también formado en Montpellier, impartió clases de Naturales en el Colegio de San Agustín, fue director y médico del Hospital de San Martín en sustitución de Domingo Déniz Greck y presidente del Partido Progresista) al Ayuntamiento de la ciudad, fechada a 21 de agosto de 1871, en la que el colectivo informaba que, en su sesión del día 12 de aquel mes, el socio Luis Navarro Pérez (1832-1891) ${ }^{9}$ propuso que:

[...] considerando la importancia y utilidad del arbolado para la salubridad y recreo de las poblaciones, [...] propone á [sic] la Sociedad de Amigos del País que, previo acuerdo con el Ilustre Ayuntamiento, se digne acordar la creacion [sic] de una Junta permanente del arbolado compuesta de individuos de la Sociedad, de vecinos de la poblacion $[s i c]$ y de individuos de la municipalidad $[\ldots]^{10}$.

Como vemos, la iniciativa de Luis Navarro Pérez respondía a un higienismo social en el que se refería al arbolado en su doble dimensión, sanitaria y moral (servir a la distracción de la población), detallando las funciones que debía tener la propuesta de Junta permanente: estudiar la población para designar los sitios que debían arbolarse, estudiar el terreno y sus condiciones y la clase de árboles que debían plantarse, levantar un plano de cada sitio con las obras de embellecimiento que la localidad requiriese y aportar recursos (por ejemplo,

8 AHPLP, Ayuntamiento Popular de Las Palmas, Arbolado y Jardines, exp. 133, Expediente sobre la creación de una Junta que entiende de la propagacion del arbolado en esta ciudad, 1871.

9 Doctor en Medicina por la Universidad Central de Madrid (1861), ciudad en la que también ejerció la profesión, fue profesor del Seminario Conciliar y del Colegio de San Agustín. Ejerció como médico del Hospital de San Martín, era asiduo a la tertulia de la Farmacia de Fernando Bojart en la calle Muro, fundó varios periódicos en defensa del partido conservador (con destacados miembros como Antonio López Botas y el citado Domingo J. Navarro, entre otros). En 1875 fue nombrado alcalde de la ciudad de Las Palmas y durante su alcaldía, y tras esta, impulsó el arreglo de los parterres de la fuente del Espíritu Santo y la urbanización y el arreglo de la plaza de Cairasco (Betancor 2016: 4).

10 AHPLP, Ayuntamiento Popular de Las Palmas, Arbolado y Jardines, exp. 133, «Sociedad de Amigos del País de Las Palmas de Gran Canaria, Num. 32», Expediente sobre la creación de una Junta que entiende de la propagacion del arbolado en esta ciudad, 21/08/1871, f. 1r.-2v. 
mediante suscripción pública mensual) para dar comienzo de forma inmediata a las plantaciones.

Pero no sorprende que fuera Luis Navarro quien propusiera la creación de la Junta mixta de arbolado si se tiene en cuenta su perfil, pues había estado en contacto, con total probabilidad, con los postulados de los citados Seoane, Monlau y Méndez Álvaro (en 1860 vio la luz la obra de este último, La lepra en España a mediados del siglo XIX. Su etiología y su profilaxia). De vuelta a Gran Canaria, Luis Navarro tuvo una presencia activa entre el grupo de médicos que trabajaba en la isla, participando en la elaboración de informes como el Análisis de las aguas de Azuaje en Gran Canaria, e informe médico sobre sus cualidades publicadas por la Sociedad de Amigos del País, que, basándose en los estudios previos de Antonio Casares, catedrático de Química de la Universidad de Santiago de Compostela, contó con la participación de otros galenos grancanarios como los mencionados Navarro Pastrana (1803-1896), Déniz Greck (1808-1877), González González (1825-1884); y otros como Gregorio Chil y Naranjo (1831-1901), Pedro Suárez Pestana (1833-1896) y Miguel de la Rosa Báez (1827-1887) ${ }^{11}$. A estos profesionales, además del hecho de haberse formado en medicina en la Península y en Francia y de ejercer la profesión en Gran Canaria, los unía su implicación política en defensa de la división provincial, amén de que coincidían en la importancia económica que suponía el desarrollo portuario y el turismo (en sus primeros años centrado en un turismo de salud, poniendo el foco en instalaciones como los balnearios $\mathrm{y}$, derivado de ello, en la importancia de los análisis químicos para conocer las propiedades terapéuticas del agua) ${ }^{12}$, tal y como sucedió antes de los años ochenta en otros puntos costeros del país como Málaga o Alicante y, con especial incidencia, en ciudades como Madrid, Barcelona, Sevilla..., en las que la insalubridad suponía un bloqueo para el desarrollo económico e industrial.

Volviendo a la propuesta de Luis Navarro de formar la Junta mixta de arbolado y, como era de esperar, esta fue estimada positivamente por la Económica, que la trasladó al Ayuntamiento, donde, en sesión municipal de 25 de agosto de 1871, se acordó su aprobación y la designación del alcalde y de los concejales, Antonio

11 Gregorio Chil y Naranjo se formó en París y, de vuelta a Gran Canaria, donde ejerció la profesión, fundó, junto a otros próceres como Domingo J. Navarro, la citada Sociedad El Museo Canario, siendo también el director de su museo de Historia natural. Pedro Suárez Pestana estudió medicina en Cádiz, fue médico titular de Las Palmas, médico director de Sanidad del Puerto y desempeñó la Subdelegación de Medicina hasta su muerte. Miguel de la Rosa y Báez se doctoró en Montpellier, ejerció la profesión en Nimes y en Gran Canaria, donde fue alcalde de la ciudad de Las Palmas durante la República y profesor en el Colegio de San Agustín y en el Instituto de Segunda Enseñanza (Chesa 2020: 56, 140-141, 146-147).

12 Esta situación se veía fortalecida, además, con la tesis que se extendió entre los médicos victorianos de que la salubridad y la higiene (como, por ejemplo, el aire limpio, el uso terapéutico de las aguas minerales y el clima cálido, junto a una buena nutrición) eran fundamentales para la recuperación de las enfermedades y la regeneración de los tejidos (González 2007: 115). 
del Castillo y Vicente Suárez y Naranjo, para la composición de la comisión mixta con los vecinos Julián Cirilo Moreno (ganador de la plaza de ayudante de obras públicas en el Ayuntamiento de la ciudad de Las Palmas, colaborando con Juan de León y Castillo en la construcción del Puerto de La Luz) ${ }^{13}$ y Francisco Perdomo. Entre los miembros que nombró la SEAPGC incluyó al citado Domingo J. Navarro, Juan Melián y Caballero (que ocupó en 1875 el puesto de contador y secretario de la sección de agricultura de la Económica y formaría parte de otros colectivos de la época como el citado Museo Canario) y Manuel de Quesada (miembro de la Junta que se formaría para la celebración, en 1862, en la ciudad de Las Palmas, de la primera Exposición Provincial de Agricultura, Industria y Artes de Canarias) (Naranjo 2016: 242, 478-479) ${ }^{14}$.

La primera reunión de la Junta permanente de arbolado tuvo lugar en las Casas Consistoriales, bajo la presidencia del alcalde José Torres Matos, el 11 de octubre de 1871. En la misma, se acordó que la presidencia la ostentaría el citado Torres y la secretaría, Julián Cirilo Moreno, con lo que la institución se aseguraba su posición en ella ${ }^{15}$. En aquella cita trataron aspectos de especial relevancia para el futuro del proyecto, como la instalación del vivero de arbolado en el solar del ex monasterio de San Ildefonso y en la huerta de la cárcel; que el arbolado, a propuesta del doctor Navarro, se extendiese a toda la jurisdicción de la ciudad; que el Ayuntamiento solicitara al Estado la propiedad del terreno que existía junto al dique; y que se arbolasen la calle Mayor de Triana y la carretera, con pinos y laureles alternados, las plazas de San Francisco y San Bernardo, con araucarias, palmas reales, laureles y pinos; el dique, con pinos y adelfas; la carretera del Puerto de la Luz, con pinos; y que se arbolara la calle de los Reyes, la trasera de la Catedral y la del Progreso (actual calle Juan de Quesada). Además, se establecía, de forma retribuida, el encargo de cuidar los árboles y hacer los semilleros, al tiempo que el alcalde se responsabilizaba de formar los viveros de laureles, pinos, araucarias y palmeras reales en los sitios destinados y Domingo J. Navarro, el de los pinos. Constituida la Junta, el director de la SEAPGC se refirió a ella en el discurso que emitió como balance de la gestión de la Sociedad con el cierre de 1871 y que fue publicado en los Anales del colectivo; y la referencia la hacía exponiendo que la comisión mixta se había creado de acuerdo con el Ayuntamiento, con el doble objeto de contribuir a hermosear la ciudad y de

13 Entre sus trabajos destacaron su labor como ayudante de obras públicas en la reforma del edificio del Gabinete Literario y la construcción del Teatro Tirso de Molina; además de realizar el plano y tasación que dividía el solar del derribado convento de San Ildefonso.

14 AHPLP, Ayuntamiento Popular de Las Palmas, Arbolado y Jardines, exp. 133, «Sociedad de Amigos del País de Las Palmas de Gran Canaria, Num. 36», Expediente sobre la creación de una Junta que entiende de la propagacion del arbolado en esta ciudad, 28-09-1871, f. 3r.-v.

15 AHPLP, Ayuntamiento Popular de Las Palmas, Arbolado y Jardines, exp. 133, «Palmas 10 de octubre de 1871», Expediente sobre la creación de una Junta que entiende de la propagacion del arbolado en esta ciudad, 11/10/1871, f. 4r.-5v. 
hacer más saludable el aire (Anales de la Sociedad Económica de Amigos del País de Las Palmas de Gran Canaria 31/12/1871: 3, 8-9, 17).

$\mathrm{Al}$ año siguiente, en una nueva carta dirigida al alcalde, la SEAPGC solicitaba que, ante el cese de los miembros que formaban parte de la comisión mixta de arbolado en representación del Ayuntamiento, aportasen el nombre de los nuevos representantes, para que se pusieran de acuerdo con los de la Económica. En sesión del 23 de diciembre de 1872, el Ayuntamiento designó a José Hermenegildo Hurtado de Mendoza y al citado Juan Massieu, que, años atrás, había presentado el proyecto de jardín de aclimatación ${ }^{16}$. Pero aquella comisión recibió cambios varios meses después, porque la Sociedad emitió una nueva carta al presidente del Ayuntamiento informando que, en sesión de 5 de abril de 1873, agregaba a la comisión mixta de arbolado a los socios Pedro Bravo de Laguna, Pedro Suárez y a los hermanos Pablo y Juan Padilla (el primero, krausista y profesor del Colegio de San Agustín; y el segundo médico) ${ }^{17}$; e igualmente proponía, en representación de los vecinos, a Jerónimo Navarro, Sebastián Lezcano y José Medina. La propuesta fue aceptada por la alcaldía, que, en sesión del 21 del mismo mes y año, informó a todos los vecinos mencionados ${ }^{18}$.

Escasos meses después de estos nombramientos, la comisión de ornato del Ayuntamiento, constituida por Rafael Millares, Juan Monzón y Castro, Rafael Pérez y, el recientemente nombrado arquitecto municipal, José. A. López Echegarreta, propuso al alcalde un proyecto de bases para el establecimiento de arbolado de sombra en la ciudad, en un momento en que se ponían las miras de expansión de esta hacia el puerto, por lo que la iniciativa afectaba al centro de la urbe (placetilla de entrada a la calle de Triana, plazas de San Bernardo, de la Democracia, del Espíritu Santo y de Santo Domingo, calle Mayor de Triana y las de Alonso Alvarado, Muro, La Carnicería, Puertas, Reyes y La Rambla) y al

16 AHPLP, Ayuntamiento Popular de Las Palmas, Arbolado y Jardines, exp. 133, «Sociedad de Amigos del País de Las Palmas de Gran Canaria, Num. 45», Expediente sobre la creación de una Junta que entiende de la propagacion del arbolado en esta ciudad, 16/12/1872, f. 6r.-v.; «Sr. Presidente de la Sociedad de Amigos del Pais de esta población», 27/12/1872, f. 7r.-v.

17 Juan Padilla Padilla (1826-1891) se formó en medicina en la Sorbona, junto a Gregorio Chil y Naranjo, con quien colaboró en la elaboración de la obra Estudios históricos, climatológicos y patológicos de las Islas Canarias. Padilla completó su formación licenciándose también en Ciencias Físicas por la Universidad de Caen y, de regreso a Gran Canaria, impartió francés en el Colegio de San Agustín. Fue alcalde de la ciudad de Las Palmas en 1871 y entre sus numerosos cargos destacaron la vicepresidencia de la Junta Superior de Sanidad de Gran Canaria, la Secretaría general de la Sociedad Económica de Amigos del País, formar parte de la Primera Junta de la Cruz Roja y haber cofundado la Academia de Ciencias Médicas (Chesa 2020: 120; Regueira 2019).

18 AHPLP, Ayuntamiento Popular de Las Palmas, Arbolado y Jardines, exp. 133, «Sociedad de Amigos del País de Las Palmas de Gran Canaria, Num. 23», Expediente sobre la creación de una Junta que entiende de la propagacion del arbolado en esta ciudad, 14-04-1873, f. 8r.-v.; «Sr. Presidente de la Sociedad de Amigos del Pais de esta población», 30/04/1873, f. 9r.-v.; «A los Sres. vecinos», 30-04-1873, f. 10r.-v.; «Por la atenta comunicacion», 03/05/1873, f. 11r.-v. 
barrio de Arenales, encargándose la comisión de la inspección de la adquisición, plantío y distribución de los árboles ${ }^{19}$. En el proyecto de bases quedaba de manifiesto la influencia de los postulados higienistas en materia de vegetación, al argumentar que el arbolado de sombra era importante por su utilidad científica, dada la conveniencia de los árboles como reguladores ambientales al suavizar las temperaturas en los días calurosos. Pero, dada la formación de los miembros de la comisión, especialmente la del arquitecto municipal, se ponía especial énfasis en el plano estético, citando como referentes de la propuesta al jardinero André Le Nôtre (jardinero del rey Luis XIV desde 1645 hasta 1700, encargándose del diseño de los jardines del Palacio de Versalles, del Palacio de Vaux-le-Vicomte y del de Chantilly, y en cuyos trabajos destacó por sus perspectivas, geometrías e ilusiones ópticas) y a los poetas y escritores John Milton (autor del poema narrativo El paraíso perdido, en el que describe un sugerente Edén inspirado en jardines antiguos) y Alexander Pope (conocido por trazar en su vivienda un jardín paisajista en el que diseñó una gruta, llena de trampantojos y artificios). Estos referentes ponen de manifiesto el propósito de la comisión de que los espacios ajardinados de la ciudad estuvieran a camino entre las formas rígidas y geométricas de los jardines clásicos franceses (caracterizados por la simetría y por la búsqueda de la teatralización del espacio, mediante el orden de la naturaleza) y la frescura del jardín paisajista inglés (identificado con la fantasía, con el ideal del viaje y con el retorno a la libertad dispositiva de la naturaleza).

Además, el proyecto establecía todo lujo de detalles en lo referente al modo en que se gestionaría, dotando a la comisión de plenas atribuciones para ubicar las especies y haciendo partícipe al vecindario. Precisaban cuestiones como que no se podía dejar a medias el arbolado en una calle o plaza para empezar a trabajar en otra; las plantaciones debían empezar por un extremo de la vía y seguir por ambos costados, sin interrupción hasta el otro extremo (a menos que los defectos de alineación permitieran continuar las filas), y en las plazas debían comenzar por un ángulo y continuar dando la vuelta sin interrupciones; la comisión propondría al Ayuntamiento, para cada calle o plaza, la distancia que debía dejarse entre el tronco de los árboles y los muros de fachada o de cerca, de lo que se informaría por la prensa a los vecinos afectados, dándoles un plazo de tres días para cursar sus reclamaciones; la institución local no quedaba obligada a consignar ninguna cuantía para el planteamiento, ejecución y sostenimiento del proyecto, pero la comisión podía promover una suscripción entre los vecinos de la ciudad (de no conseguirse, se daría parte a la municipalidad, pero si, fruto de la recaudación, sobrasen fondos, se reservarían para ampliar el proyecto o para mejorarlo, manteniendo informado igualmente al público), que serían los encargados del riego de los árboles de su calle o plaza, previa asignación de un

19 AHPLP, Ayuntamiento Popular de Las Palmas, Arbolado y Jardines, exp. 133, «Exmo. Ayuntamiento de la ciudad de Las Palmas», Expediente sobre la creación de una Junta que entiende de la propagacion del arbolado en esta ciudad, 25/09/1873, f. $12 \mathrm{r} .-15 \mathrm{r}$. 
número de los que les correspondía, hasta que el Ayuntamiento pudiera hacerse cargo presupuestariamente; y la comisión elegiría también dónde ubicar un pequeño vivero de árboles, de lo que informaría puntualmente a la institución.

El proyecto de arbolado contemplaba, además de la actuación en las zonas centrales de la ciudad, una propuesta para los solares cedidos por el Ayuntamiento fuera del casco, supeditando la pertenencia de estos al cumplimiento del programa. Este subproyecto obligaba a plantar árboles de sombra frente a las fachadas de las casas, cuyo número se establecería por la comisión y el Ayuntamiento, sin que pudieran ser menos de dos. En caso de que las condiciones de la vía no permitieran la plantación, se estaría en la obligación de hacerlo en el patio de las viviendas; el concesionario quedaba obligado a cuidar, cultivar, regar y podar los árboles que le correspondieran y, en el caso de que alguno de ellos muriera, independientemente de la causa, quedaba obligado a reponerlo, incluso en el caso de que se dispusiera de él por herencia, venta o cesión gratuita.

Una vez presentada la propuesta al Ayuntamiento, este estableció que debía ser tratada entre la comisión de ornato y la Junta mixta de arbolado y, aunque desconocemos si aquella reunión se produjo, de lo que sí tenemos constancia es de que Domingo J. Navarro hizo anotaciones, a modo de reglamento, al proyecto de la comisión, indicando que no se debía dejar a su cargo la adquisición de arbolado porque «[...] nunca se conseguirá el resultado, como lo acredita la esperiencia $[s i c]$ de los tres años trascurridos inutilmente $[\ldots] »^{20}$. En aquel borrador, Navarro proponía poner el peso de las actuaciones en la institución municipal a través de la Junta mixta -planteando la distribución del número y especie de árboles que se necesitasen entre los propietarios o establecer un vivero en un local oportuno-. Pero, en lo relativo a la forma de asumir el coste de la propuesta, se aclaraba que una suscripción sería ineficaz y que el Ayuntamiento debía consignar la partida anual para ello. Además, se sugería que un municipal se encargara periódicamente del cuidado y riego de los árboles ${ }^{21}$.

Finalmente, en un contexto en el que paralelamente se trabajaba en la idea urbanística del ensanche ${ }^{22}$, para la que también se creó una comisión mixta de la que formaba parte la SEAPGC, la Junta mixta de arbolado fue convocada por la alcaldía el 5 de marzo de 1874, constituyéndola por aquellas fechas el teniente de alcalde Agustín Bravo y Joven, los concejales Francisco León Quevedo, Antonio Eduardo Santana y Pedro Hernández López, y el arquitecto López Echegarreta,

20 AHPLP, Ayuntamiento Popular de Las Palmas, Arbolado y Jardines, exp. 133, "Anotasiones al proyecto de arbolado», Expediente sobre la creación de una Junta que entiende de la propagacion del arbolado en esta ciudad, s/f, f. 16r.-v.

21 AHPLP, Ayuntamiento Popular de Las Palmas, Arbolado y Jardines, exp. 133, "Anotasiones al proyecto de arbolado», Expediente sobre la creación de una Junta que entiende de la propagacion del arbolado en esta ciudad, s/f, f. 16r.-v.

22 Este propósito no vio la luz hasta 1888, cuando el Ayuntamiento convocó un concurso para la presentación del proyecto de ensanche de la población (Anales de la Sociedad Económica de Amigos del País de Las Palmas de Gran Canaria 31/12/1873: 6). 
en nombre del Ayuntamiento. En representación de los vecinos se encontraban Jerónimo Navarro y Sebastián Lezcano; y por la SEAPGC, un elenco de médicos, con Domingo J. Navarro a la cabeza y seguido por Juan Melián y Caballero, Manuel de Quesada, Pedro Bravo y Joven, Pedro Suárez Pestana y los hermanos Juan y Pablo Padilla Padilla ${ }^{23}$. Una representación política, técnica y médica que aseguraba la triple mirada del proyecto: político, urbano-estético, e higiénicosanitario.

Aquella misma noche de marzo, una parte de la comisión mixta se reunió ${ }^{24}$ en las Casas Consistoriales para analizar, bajo la presidencia del alcalde Felipe Massieu, el proyecto presentado por la comisión de ornato y el reglamento de enmiendas, y concluyó que el proyecto de la comisión sería aprobado con las siguientes modificaciones: en los diferentes artículos del proyecto, donde decía comisión de ornato, se substituiría por comisión mixta, volcando todo el peso en esta última, que sería la encargada de establecer el arbolado de sombra en la placetilla de entrada a la calle de Triana, las plazas de San Bernardo, de la Democracia, del Espíritu Santo y de Santo Domingo, las plazoletas de San José y San Nicolás y las calles Muro, Rambla y Progreso. También se eliminaba la suscripción para hacer frente a la compra de arbolado, y se confirmaba el papel del Ayuntamiento en este asunto, previo informe de la comisión mixta que indicaría la tipología de árboles que se debían adquirir. Igualmente, se eliminaban los artículos relativos a la obligación del vecindario a hacerse cargo del riego y del cuidado de los árboles. Por último, se proponía, ante la existencia de una vacante en la comisión mixta por el fallecimiento de José Medina, la incorporación del hijo de Domingo J. Navarro, el también médico (formado en Madrid y París) Andrés Navarro Torrens, «[...] por las circunstancias que en él concurrían ${ }^{25}$ imponiéndose el criterio y el peso de su padre en el plan de arbolado, frente al propuesto por la comisión de ornato.

La siguiente reunión de la comisión mixta tuvo lugar en las Casas Consistoriales, bajo la presidencia del alcalde, en el mes de septiembre de 1874 . En ella, se decidió que se preparasen para el plantío las zanjas de las calles de Alonso Alvarado, Muro y las plazas del Muelle, de San Bernardo y de Santo Domingo, guardando entre sí una distancia de siete metros, y que se iniciasen

23 AHPLP, Ayuntamiento Popular de Las Palmas, Arbolado y Jardines, exp. 133, «Palmas 5 de marzo de 1874», Expediente sobre la creación de una Junta que entiende de la propagacion del arbolado en esta ciudad, 05/03/1874, f. 17r.-18v.

24 AHPLP, Ayuntamiento Popular de Las Palmas, Arbolado y Jardines, exp. 133, «Reunida la Comisión mista de arbolado», Expediente sobre la creación de una Junta que entiende de la propagacion del arbolado en esta ciudad, 05/03/1874, f. 19r.-20v. No asistieron, posiblemente por la premura de la convocatoria, Hernández, en representación del Ayuntamiento; ni Navarro, Melián, Bravo y Suárez, por la Económica; y ninguno de los dos vecinos mencionados.

25 AHPLP, Ayuntamiento Popular de Las Palmas, Arbolado y Jardines, exp. 133, "Certifico: que del acta de la sesion», Expediente sobre la creación de una Junta que entiende de la propagacion del arbolado en esta ciudad, 12/05/1874, f. 21r.-v. 
las plantaciones en los meses de noviembre y diciembre. Pero también se decidió que se pidiese a Valencia, al famoso establecimiento de horticultura de J. Felix Robillard $^{26}$ (jardinero jefe de los Campos Elíseos y jardinero mayor del Botánico de Valencia), un encargo compuesto por quinientas acacias blancas, quinientas acacias de tres espinas, cien pinos de Alepo, cien pinos de Austria, treinta adelfas, cien gatillos, cien mundillos, por el precio total de 980 reales de vellón ${ }^{27}$; un pedido que, como vemos, incluía plantas llamativas por sus colores y aromas, pero que también contemplaba algunas con propiedades antibacterianas y fungicidas como los pinos.

\section{Acciones futuras en la vegetación urbana. El papel de la familia Navarro}

Como hemos visto, en la mayor parte de las propuestas que se desarrollaron en la ciudad en materia de arbolado, desde la propuesta del jardín de aclimatación hasta la creación de la comisión mixta, Domingo J. Navarro siempre estuvo, de forma directa o indirecta, en las gestiones o en relación con el resto de médicos de la Isla que llevaban a cabo actuaciones en materia de plantaciones urbanas. Por eso, no es de extrañar que su hijo, Andrés, siguiera sus pasos en una época en la que el arbolado fue adquiriendo mayor peso en la trama urbana (en 1875, López Echegarreta elaboró el Proyecto de reformas de las plazas de la ciudad), no solo incluyéndolo en la Junta mixta sino también nombrándolo titular de la Dirección de arbolado y jardines públicos de la urbe y principal impulsor, en 1876, de la recuperación como espacio de ocio del terreno del actual parque de San Telmo, de cuya gestión decía José Suárez ón «[...] el parque y otros paseos los embellece con árboles, flores y animales vistosos. De nuestra niñez conservamos la visión del flamenco y los patos que nadaban en el pequeño estanque del parque, todavía sin ensanchar hacia el mar, con los antiguos astilleros donde se construían barcos [...]» (Suárez s.f.: 23). Además, en abril de 1877, Navarro Torrens asumió la responsabilidad de la Alameda tras la muerte de Domingo Déniz Greck, puesto que ocupó hasta su fallecimiento (a excepción del periodo 1888-1891, en que residió en México), y presentó al Ayuntamiento

26 Jean Felix Robillard Closier (1812-1888), formado en el Institut Horticole de Fromont y en el Jardin de Plantes de París, se afincó en Valencia en 1848 como jardinero mayor del Botánico (a él se debe su reordenación y el diseño de los invernaderos). En la ciudad valenciana impulsó el cultivo del geranio malvarrosa (a quien debe su nombre el barrio de la Malvarrosa) y puso en marcha el afamado establecimiento de horticultura y una fábrica de jabones de tocador y esencias que, a escala industrial, se hizo pionera en España, siendo la primera en Valencia de jabones tocadores y perfumería. Además, destacó por la divulgación científica de sus trabajos en numerosas publicaciones (García 2012).

27 AHPLP, Ayuntamiento Popular de Las Palmas, Arbolado y Jardines, exp. 133, «Reunida en las Casas Consistoriales á diez», Expediente sobre la creación de una Junta que entiende de la propagacion del arbolado en esta ciudad, 19/09/1874, f. 22r.-v. A la reunión asistieron el citado alcalde, Felipe Massieu y Falcón, Domingo J. Navarro, Pedro Suárez Pestana y Juan Melián y Caballero. 
un borrador de reglamento del arbolado y jardines públicos de la ciudad que, derivado a la comisión mixta, fue aprobado para su traslado al Ayuntamiento para su conforme, si así lo estimaban ${ }^{28}$.

Aunque no nos ocuparemos de ello en este texto, no podemos pasar por alto que la aprobación y puesta en marcha de aquel reglamento supuso una nueva fase en la vegetación de los espacios públicos de la urbe, estructurando la zona central de la ciudad frecuentada por la burguesía. Así, a finales de siglo, mientras la ciudad se dirigía hacia la zona del puerto, en el otro extremo se siguió trabajando en el arbolado con proyectos como las propuestas para las plazas de Santo Domingo, la del Ingeniero León y Castillo (hoy Plaza de La Feria), el proyecto para el arbolado de Vegueta, etc. Estos avances hicieron que Domingo J. Navarro describiera la urbe, en los últimos años de la centuria, como expectante ante la definitiva construcción del Puerto de La Luz (sus obras habían comenzado en 1883) y el gran desarrollo demográfico. Afirmaba, en clave comparativa entre comienzos de siglo y las últimas décadas, que:

al desierto de arena que se extendía desde aquel solitario puerto hasta la ciudad; espléndidos hoteles, quintas de recreo, preciosos jardines, numeroso arbolado, innumerables casas y una buena carretera concurridísima [sic] A la falta absoluta de paseos y aún de caminos vecinales, hermosos paseos, deliciosos jardines públicos y tres carreteras generales que salen de la ciudad y cruzan la isla (Navarro 1895: 138, 170-171).

Además de esta publicación, Domingo J. Navarro escribió como obra culmen de su carrera, Consejos de higiene pública a la ciudad de Las Palmas, que vio la luz el mismo año de su fallecimiento, en 1896, en la que recogía, a modo de resumen de los conocimientos adquiridos a lo largo de su vida, varias reflexiones para la mejora de la salubridad de la urbe, entre las que las referencias al arbolado no faltaron. Sobre el ensanche de la ciudad, en el barrio de San José, sugería que se dotara de árboles frondosos, a ser posible en las dos cunetas, para refrigerar las viviendas, y que, además, se reconvirtieran las abandonadas lomas en un bosque donde predominaran los pinos marítimos y los eucaliptos, cuya frescura y emanaciones sanearían la población. En términos similares se refería

28 AHPLP, Ayuntamiento Popular de Las Palmas, Arbolado y Jardines, exp. 133, «Dirección del Arbolado y Jardines Públicos de Las Palmas. Num. 1», Expediente sobre la creación de una Junta que entiende de la propagacion del arbolado en esta ciudad, 19/05/1877, f. 23r.-v.; Ibídem, «Se convoca á los Señores expresados», 19/05/1877, f. 24r.-v.; AHPLP, Ayuntamiento Popular de Las Palmas, Arbolado y Jardines, exp. 133, «Reunida en las Casas Consistoriales», Expediente sobre la creación de una Junta que entiende de la propagacion del arbolado en esta ciudad, 19/05/1877, f. 25r.-v.; AHPLP, Ayuntamiento Popular de Las Palmas, Arbolado y Jardines, exp. 133, «Excmo. Sr: La comision mixta de Arbolado», Expediente sobre la creación de una Junta que entiende de la propagacion del arbolado en esta ciudad, 19/05/1877, f. 26r.-v. Por aquellas fechas, la Comisión mixta de arbolado la formaban el propio Andrés Navarro Torrens, Domingo J. Navarro, Juan Melián Caballero, Juan y Pablo Padilla, Pedro Suárez Pestana, Manuel de Quesada, Jerónimo Navarro, Sebastián Lescano y el Arquitecto municipal Echegarreta. 
a Los Riscos del barrio de Triana, de los que sugería vigilar su sanidad y plantar uno o dos árboles delante de las casas para dotarlas de sombra. Al centrarse en los paseos y arbolados, Navarro destacaba los de Colón, San Telmo y La Plazuela porque, aunque pequeños, eran buenos y agradables para el recreo en las noches de verano. De entre los tres, resaltaba la ubicación y excelente sombra, a todas horas, del paseo de San Telmo, que requería un ensanche para alejarlo del astillero, y por el decoro que ello supondría para la principal entrada a la ciudad. Por otra parte, para los paseos largos, proponía el camino que se hallaba al pie de la colina del barrio de Arenales, que sugería llamar Vista Alegre por el excelente paisaje que desde él se vislumbraba, apuntando que se destinara únicamente para los viandantes y que se armara de árboles en sus orillas e incluso de kioscos. Las reflexiones del anciano médico concluían afirmando que:

El arbolado público es el mejor y más higiénico adorno de las poblaciones y debe extenderse á todos los sitios donde haya capacidad para colocarlo. Desde luego lo está exigiendo la carretera del Puerto de La Luz y no dudamos que el entendido y digno Ingeniero de Obras Públicas emprenderá esa urgente reforma en una carretera tan importante que debió ser la primera en ostentar un magnífico arbolado. La placeta de Stagno está pidiendo misericordia á [sic] quien quiera hacerle la caridad de reformarla en beneficio de la higiene pública y del Teatro de Tirso de Molina tan mal tratado con las infracciones de los preceptos higiénicos en desdoro de sus riquezas arquitectónicas (Navarro 1896: 23-24, 138).

Tras la muerte de Domingo J. Navarro y la renuncia del doctor Bartolomé Apolinario Macías, Andrés Navarro Torrens fue elegido, por unanimidad y en sesión municipal ordinaria de 6 de septiembre de 1899, nuevo director de Higiene de la ciudad. Impulsó labores en el campo del higienismo urbano como la inspección de locales y domicilios (1901) en los que pudieran concurrir malas condiciones higiénicas; una reforma (1902) de la planificación del saneamiento viario por su conciencia de las malas condiciones de aseo y limpieza de los barrios de la urbe, en comparación con los de Vegueta y Triana, poniendo sus mayores desvelos en la zona del puerto al tratarse del más populoso de los barrios y por ser un foco de gérmenes infecciosos por los tugurios de La Isleta y las calles taponadas, sin pavimentar, sin alcantarillado y sin agua (Martín 2007: 61-64). En definitiva, tal y como lo describió Suárez Falcón, puede decirse que el doctor Andrés Navarro defendía la salud pública evitando la propagación del mal; confeccionaba mapas sanitarios con los focos de infección, gráficos y estadísticas que lo orientaban en sus campañas higiénicas; escribía memorias sobre el estado sanitario de la urbe y «[...] su última hazaña fué [sic] encerrarse entre los muros del Lazareto de Gando, para asistir a los atacados de gripe del vapor «Infanta Isabel», en 1918 [...] por el cual se le concedió la Cruz de Beneficencia [...]» (Suárez 194??: 29-30). 


\section{El verde público en Santa Cruz de Tenerife}

En el siglo XVIII, se produjeron grandes avances en materia de botánica, con estudios que versaban sobre la fisiología vegetal, la sexualidad de las plantas y la obra de Carl von Linné y su aportación a la taxonomía botánica, entre otros. En España, la botánica también vivió un momento álgido durante la Ilustración al publicarse diversos tratados, fundarse el Jardín Botánico de Madrid y realizarse importantes expediciones científicas enfocadas al estudio de la flora de la América hispana en la búsqueda por el mantenimiento del imperio colonial, mediante la revalorización del conocimiento y la explotación de sus riquezas naturales y con el fin de mantener el control efectivo de su producción y comercialización (Herrera 2006: 62).

En este contexto, y a raíz de la Real Orden de 17 de agosto de 1788, se fundó en La Orotava, Tenerife, el jardín de aclimatación de plantas, cuyo objeto era cultivar las semillas de América y Filipinas para introducirlas posteriormente en los jardines reales y en los jardines botánicos del país, y que quedó bajo la responsabilidad administrativa de Alonso de Nava Grimón y Benítez, VI Marqués de Villanueva del Prado. Desde finales de aquella centuria, y hasta comienzos de la nueva, aquel jardín consiguió gran prestigio, no solo por los contactos que mantenía y las visitas que recibía de investigadores como Humboldt, Bonpland, Von Buch y Barker Webb, sino también porque, como hemos visto, en aquella época, el espacio arbóreo y vegetal comenzaba a despertar gran interés, al tiempo que las ciudades canarias también vivían su florecimiento.

En la segunda mitad del siglo xIx, tal y como afirma Castro Molina (Castro 2012: 169), Santa Cruz de Tenerife era una urbe con malas condiciones higiénicas y de salubridad porque, a la ausencia de desagües que ayudaran a eliminar los desechos de la vida diaria, se sumaba el hecho de que los barrancos y las viejas alcantarillas evacuaban las aguas residuales en las playas, proliferando los focos de infección dentro y fuera de la ciudad y haciendo el tránsito por sus calles poco agradable. A este panorama se unía la carencia de ordenanzas municipales, que sumían al territorio en una penosa situación.

A las afueras de la ciudad, por el contrario, tenemos constancia a través de la prensa de que, desde marzo de 1857, el estado de los árboles que se habían plantado a la orilla de la carretera en la salida de la urbe era bueno, solicitando el riego y cuidado de ellos para asegurar su prosperidad y uniformidad (Eco del Comercio 29/03/1857: 1) ${ }^{29}$. En septiembre de 1857, el mismo periódico informaba de un proyecto que pretendía cubrir de verdor las laderas que circundaban la capital para mejorar su aspecto, plantando un tipo de nicociana (planta del tabaco) que era de reciente importación y que se había aclimatado a la perfección en las zonas marítimas de la Isla. No obstante, dado que, según la

29 Por un suelto del valenciano Vicente Bonnet sabemos que algunos de aquellos árboles se perdieron al año siguiente, por la falta de cuidados en su primera etapa (Eco del Comercio 16/01/1858: 1). 
prensa, aquella planta no daba otro provecho que el estético, proponía, con la colaboración de la Junta de Agricultura, al Gobernador Civil que se plantara en las laderas otro tipo de vegetación, como el algarrobo, que, además de bello, daba un fruto bueno para alimentar y engordar al ganado, o algunas especies de pinos (Pinus maritima, halepensis, sylvestris, pinacea, laricio o pinea), que, tal y como había sucedido en el litoral del Mediterráneo, podían aclimatarse en la ciudad y en la cordillera de Añaza (Eco del Comercio 27/09/1857: 1).

El ejemplo de estas iniciativas y mejoras a las afueras de la urbe, junto a las posibilidades que abrió la desamortización, debieron servir de empuje para que en el núcleo de Santa Cruz de Tenerife se habilitaran nuevos espacios públicos en los que la vegetación fue un tema constante. Este fue el caso, por citar algunos ejemplos, del espacio ocupado por el convento dominico de la Consolación, que aglutinó en su entorno la formación del nuevo barrio de Vilaflor o de la Consolación, formado por las calles de Miraflores, Canales (hoy, Ángel Guimerá), Santa Isabel (hoy, Carmen Monteverde) y Consolación (Puerta Canseco), y en el que se construyeron (1851), abriéndose a una plaza, el Teatro Municipal, hoy, Teatro Guimerá, como alimento de civismo y educación, y la Recova, hoy, Centro de Arte La Recova, como lugar de distribución y transacción higiénica y salubre. Por otro lado, sobre las huertas del desamortizado convento franciscano San Pedro de Alcántara, se construyó la alameda del Príncipe de Asturias que, junto a la alameda del Duque de Santa Elena cubriría las horas de recreo de los viandantes, como tendremos ocasión de tratar más adelante. La alameda del Príncipe, hoy plaza del Príncipe, fue proyectada por el arquitecto Manuel de Oraá y Arcocha sobre la huerta del desamortizado convento de San Pedro de Alcántara (actual iglesia de San Francisco) e inaugurada en 1860, ocupando una importante zona urbana para la planificación posterior (al igual que la alameda de la ciudad de Las Palmas, disponía de varios paseos internos que regulaban el acceso de los distintos grupos sociales). En paralelo a estas intervenciones urbanas, se acometieron también algunas medidas en materia de arbolado en lo que hoy sería el centro de la ciudad, como el proyecto que pretendía dotar de árboles a la calle que iba desde la denominada Cruz de San Agustín hasta cerca de la Maestranza de Artillería (en el actual entorno de la plaza Weyler); las obras del paseo proyectado en el camino o paseo de Ortega, hoy La Rambla (construida desde 1661 por el capitán general Gerónimo de Benavente y Quiñones y ampliada en 1854 por el capitán general Jaime Ortega, en una avenida de tres carriles con 336 árboles que ofrecían sombra a la población); y el arranque de las mejoras de acondicionamiento del puerto de Santa Cruz en 1895, aunque el Estado había asumido la necesidad de su reparación desde 1847 (Eco del Comercio 16/06/1858: 1; 02/04/1859: 1; González 1996: 84-85).

El progresivo aumento del tráfico portuario, al igual que sucedió en la ciudad de Las Palmas, trajo consigo entre las décadas de los años setenta y ochenta del siglo xIx, la instalación de compañías mayoritariamente extranjeras (caso de consignatarias como Hamilton and Co. y Forzasen Frenes, entre otras), el nacimiento de nuevos servicios y la llegada de nuevas nacionalidades que fueron 
transformando el comercio, la producción agrícola, la urbe y la arquitectura, los servicios públicos, el gusto, el ocio y la cultura, para satisfacer los intereses de la burguesía extranjera y local, y mostrarse al mundo como una urbe moderna e higiénica, propia de una capital de provincia. En consecuencia, en este periodo de la segunda mitad del siglo XIX, se acometieron una serie de reformas arquitectónicas y urbanas, como la prolongación de la calle Castillo, que enlazaba con la plaza Weyler (realizada, en 1893, por Vicente Armiño e impulsada por el Ayuntamiento de la localidad, la Capitanía General de Canarias y por la Constructora de Edificios Urbanos), al actuar esta como punto de fuga de aquella; y, desde la plaza de Weyler, partían las vías que comunicaban el extrarradio de la ciudad con el casco histórico, como la carretera de La Laguna. Por otro lado, la plaza de la Candelaria (también llamada plaza del Castillo, de La Pila, Real y de la Constitución, fue creada desde el siglo xvi, pero fue en el siglo XVIII cuando se convirtió en el centro neurálgico de la urbe, al ubicarse en ella el poder administrativo, militar y socioeconómico), hasta que en el siglo XIX se transformó en el centro civil y comercial con la instalación de un café afrancesado, hoteles, bodegas y tiendas. Completaban la urbe las viviendas burguesas del centro histórico y, en contraposición, las humildes casas de la periferia en los barrios de El Toscal, el barrio obrero Duggi y El Cabo; y, a las afueras de la ciudad, al sur, el cementerio de San Roque y San Rafael, como parte de los postulados higienistas de la época (González 1996: 88-89).

\section{Las alamedas y plazas como puntos de expansión del arbolado}

Fue precisamente dentro de los postulados higienistas, y en el marco de lo decorativo, donde el arbolado ocupó un papel de primer orden en el desarrollo de Santa Cruz de Tenerife y, especialmente, en las alamedas y en las plazas, que incorporaban la naturaleza junto a las fuentes y esculturas para disfrute de la población, convirtiéndose en verdaderos pulmones urbanos y en una parte importante de la ciudad, hermoseada y salubre, que se abría al mar.

Dentro de los espacios arbolados que se deben destacar sobresale la citada alameda del Duque (también conocida como la alameda del Muelle, de la Marina o Los Paragüitas), que se llevó a cabo en 1787 por iniciativa del comandante general de la Isla, Miguel de la Grúa Talamanca de Carini y Branciforte, y que fue realizada por el ingeniero militar Amat de Tortosa, al gusto de los jardines ilustrados europeos como espacio acotado para el paseo, engalanado con plátanos del Líbano y algunos tamarindos y varios objetos decorativos como una fuente de mármol de Carrara. En la segunda mitad del siglo XIX, la Alameda se había convertido en un paseo agradable y frondoso con flores y árboles por el que transitar; por lo que algunos miembros de la burguesía local, como el citado impresor Bonnet, reclamaban su iluminación para los paseos nocturnos del verano (Eco del Comercio 02/06/1858: 2). Algunos visitantes extranjeros, como Olivia Stone, describieron el ambiente dentro del parque como muy atractivo, tratándose de «una avenida recta que forma un paseo [que] estaba muy bien 
iluminada por lámparas de aceite colgadas a ambos lados [...]». Por el contrario, el cónsul británico Richard F. Burton decía: «[... ] alameda local, "El Maydan”, o paseo, un espacio polvoriento con muros altos, como los jardines de Florián de la actual britanizada Malta [...]»(González 2009: 220).

Con el tiempo, la alameda del Duque fue cada vez más frecuentada por el vecindario, por lo que hubo que buscar paseos alternativos que desviaran parte del ocio de la población a otro punto. Este fue el caso del paseo de la Concordia que, en 1838, impulsó el comandante general de Canarias, Juan Manuel Pereyra y Soto-Sánchez, Marqués de la Concordia. El Marqués quiso poner remedio a los desbordamientos del barranco de Santos, a raíz del ocurrido en 1826, construyendo un muro de contención de las aguas en el margen izquierdo que protegiera las viviendas de la zona y a la iglesia de la Concepción. La obra dio lugar a una explanada con acceso por la calle de la Noria, y a la plantación de acacias y moreras, para disfrute de las horas de recreo de la sociedad santacrucera. A pesar de estas obras, los desprendimientos del muro de la zona no cesaron y el abandono de la misma, unido a las malas condiciones higiénicas del agua del barranco, provocaron que no se convirtiera en la zona de afluencia que se esperaba y que la prensa se pronunciara en repetidas ocasiones sobre el mal estado del muro, los asientos, la falta de alumbrado y su arbolado por la falta de cuidado y riego. No tenemos constancia de que se acometieran mejoras en la zona hasta 1863, gracias a la labor del encargado del paseo Francisco Mandillo, y de Claudio Martinón, que no solo abarcaron avances en el paseo sino también en la calle de la Noria, que fue repoblada (El Fénix, 23/07/1858: 2; 27/02/1859: 2; Eco del Comercio 30/07/1862: 1; 26/08/1863: 2; 10/10/1863: 2; 16/01/1864: 1; 27/04/1864: 2; El Guanche 30/08/1863: 2; 23/02/1864: 1; El Mensajero de Canarias 06/06/1866: 1) ${ }^{30}$. Dadas estas circunstancias, la alameda del Duque siguió siendo la zona de mayor concurrencia para el recreo de la población de la ciudad, pero su proximidad al mar ocasionó el deterioro y muerte de su vegetación y la del paseo de Ravenet en la calle de la Marina (impulsado en 1860 por el entonces gobernador militar Joaquín Ravenet Marentes, fue primero llamado paseo de Naranjos y después, Rambla de Ravenet, encargándose de su diseño de árboles el citado Hermann (Eco del Comercio 29/01/1862: 2).

Todo ello, unido a la construcción de la alameda del Príncipe de Asturias (también conocida como alameda del Príncipe Alfonso, plaza Alameda del Príncipe de Asturias, alameda de la Libertad y hoy plaza del Príncipe), trasladó la concurrencia de la población a esta última, aunque la ampliación posterior de la zona portuaria y la consecuente ganancia de terrenos al mar hicieron

30 En 1867, el Ayuntamiento propuso la eliminación del Paseo de la Concordia con la intención de convertirlo en solares para la construcción de viviendas, argumentando que aquel sitio era bueno para la construcción de casas por su ventilación, por ser la continuación de la calle La Noria, por estar el paseo en decadencia, porque el agua que se empleaba en sus árboles podía ser aprovechado para otros y porque con su supresión se ahorraban un sueldo; justificaciones que ocasionaron de inmediato la respuesta en contra de la prensa (Eco del Comercio 16/10/1867: 1). 
recuperar la arboleda de la antigua alameda. La alameda del Príncipe fue un centro fundamental de la reestructuración viaria del barrio de El Toscal y de su comunicación con el centro de la urbe. Desde finales de 1859, la prensa del momento advirtió de la necesidad de reunir plantones para el arbolado de aquel espacio (Eco del Comercio 12/10/1859: 2), hasta que Oraá presentó el plano de la Alameda y proyecto de Alineaciones y Rasantes de las calles colindantes, en 1860, para crear una plaza pública como núcleo originario. La forma cuadrilátera de la plaza imponía un diseño de líneas rectas y, aunque no se convirtió en la plaza mayor a la que aspiraba Oraá, sí supuso una nueva forma de entender la incorporación de la naturaleza a la urbe, con una concepción de la arquitectura del paisaje a caballo entre la alameda, propia de la Ilustración, y el parque del siglo xix. Así, la alameda del Príncipe se ideó como un jardín cerrado, delimitado por un muro de sillería con enverjado de hierro, que en su interior disponía de paseos circulares y rectos que armonizaban con los plátanos del Líbano y con los laureles de indias que en 1866 se trajeron de Cuba y que, a su vez, fueron comulgando con el resto de elementos decorativos del lugar.

Recién inaugurada la Alameda, la prensa se preocupó de su estado porque las obras no se habían concluido informando, en relación con el arbolado, que gozaba de un gran desarrollo, lo que hacía del lugar un sitio agradable y pintoresco (El Guanche 16/05/1861: 1; 21/09/1861: 2). Pero, en 1862, los diarios advirtieron de que, a pesar de su lozanía, los árboles se habían empezado a cubrir de un color amarillento, a perder algunas de sus hojas, a marchitarse y a estropearse e inclinarse las acacias; el motivo, desconocido, lo achacaban al excesivo calor del estío y a que no se regaban con frecuencia, con lo que el periódico El Guanche se ofreció a aportar 8 reales de vellón todas las semanas (el importe correspondiente a una hora de agua para aljibes) para la conservación de la vegetación, animando a quien quisiera contribuir. En 1863, se acometieron varias obras de explanación en la zona, que se concluyeron al año siguiente. Pero la prensa se percató de algunas mejoras que eran necesarias en la vegetación, como quitar las plantas de girasol que en ella se encontraban por los perjuicios que ocasionaban a los árboles y lo raquítico de estos, estado que podía deberse a que, con las obras, se hizo una excesiva rebaja del terreno y se extrajo mucha tierra de las calles, con lo que las zanjas se llenaron de escombros y, en consecuencia, los árboles se encontraban en una faja de tierra de poco ancho, sin subsuelo y con grandes filtros laterales. Por eso, proponían tratar la vegetación de la zona con estiércol podrido y riegos frecuentes, pero cortos. No sabemos si la idea se acometió o si se llevaron a cabo otras medidas, pero lo que sí podemos confirmar es que una parte del arbolado de la alameda del Príncipe mejoró, mientras que otra se perdió (El Guanche 06/08/1862: 2; 30/08/1862: 2; 30/08/1863: 2; Eco del Comercio 30/05/1863: 1; 21/05/1864: 1; 01/06/1864: 1; 27/09/1865: 2).

Así y con todo, la alameda del Príncipe se convirtió en el vergel de Santa Cruz de Tenerife, describiéndola el naturalista Konrad H. Heinrich Christ como «[...] un gran jardín público en la parte alta de la ciudad, al que dan sombras unos magníficos árboles tupidos y siempre verde [...] Aquella Alameda está 
concebida con mucho gusto; está muy limpia, y la gente disfruta paseando allí por las tardes [...]». El escritor Jules Leclercq, por su parte, decía que «[...] no había en España alameda comparable [...] verdadero jardín de Arminda [...] está sombreado por magníficos laureles de indias que, en pocos años, han alcanzado la altura de nuestros viejos robles. Esta es la perla de Santa Cruz [...]» (González 2009: 220).

\section{La prensa y su importante papel en la implantación del arbolado en Santa Cruz}

Así, al igual que pasaba en el resto del país, el arbolado había ido tomando mayor peso en el espacio urbano por sus múltiples beneficios y, especialmente, por la mejora que suponía para la salud, hasta el punto de que, en un artículo sobre el fomento del arbolado que publicó el Eco del Comercio en 1861 se llegaba a afirmar que:

No podemos suponer ni por un momento que el gobierno ignore las poderosas razones en que se apoya la conveniencia de fomentar el arbolado. Todo el mundo sabe la favorable afluencia que ejerce en la salubridad del clima y la fecundidad del terreno, por la propiedad que tiene de purificar el aire y atraer las lluvias. Aun cuando hubieran $[s i c]$ otras razones, y otras muchas que por sabidas omitimos, estas dos debieran bastar para asegurarle la proteccion [sic] y el apoyo del gobierno (Eco del Comercio 12/10/1861: 2).

De esta forma, la prensa se iba impregnando progresivamente de los principios higienistas e iba retratando el acontecer de la vegetación en la zona central de la ciudad describiendo cómo, por ejemplo, el paseo o rambla de Isabel II (tramo que transcurría desde Viera y Clavijo hasta Almeyda y que era conocido anteriormente como camino de los Coches) se había dotado de dos calles de árboles, que con el tiempo estaban bien frondosos, utilizando una de las vías como zona frecuentada para pasear por lo agradable del lugar y por las excelentes vistas que tenía hacia las Huertas de Casalón (propiedad del Marqués del Duero) y, todo ello, a pesar del polvo del camino y del tránsito de carruajes y caballerías en el paseo (Eco del Comercio 11/06/1862: 2; 16/04/1864: 2). De la plaza del Teatro decían que, diez años después de haberse construido el coliseo, se encontraba en el mismo estado que cuando se inauguró, con el suelo inclinado y lleno de irregularidades, por lo que proponían solucionarlo por la afluencia de población local y visitante que concurría a la zona. Para embellecer la plaza proponían tres hileras de árboles colocados a lo largo del emplazamiento por su frente y una por el costado de la calle de la Luz, regándolos con el agua que se desperdiciaba de la fuente próxima (El Guanche 26/07/1862: 1; 30/08/1862: 2).

Sin embargo, la prensa no solo se ocupó del arbolado del centro de la ciudad, sino que también puso el foco en los alrededores de esta. Así, nos encontramos desde una editorial del diario santacrucero El Fénix que, como medida de higienismo social, se ocupaba del arbolado en las cárceles, proponiendo que se formaran alamedas o paseos dentro de estas, con vegetación, de manera que 
los reclusos pudieran hacer en ellos algunas horas de ejercicio para mejorar su estado físico y mental y respirar una atmósfera más pura (El Fénix... 14/07/1863: 1). Hasta otro artículo, por su parte, se centraba en el aspecto más estético de los paseos y de la vegetación, como expresión de un escenario al que los actores, la población, iban para ver y ser vistos y en el que, por lo tanto, debían estar ataviados al gusto de la moda europea:

hemos tenido el placer de ver nuestra bonita Alameda favorecida con la concurrencia de las hijas de Santa Cruz. El ambiente fresco y puro con que nos brinda su recinto cubierto por los hermosos árboles que le adornan y la resplandeciente luz con que se halla iluminada, la hacen el sitio mas á propósito para paseo en la estación presente; y en él pasamos alegres un momento en que olvidamos nuestras penas contemplando aquel cuadro animado, donde las dulces palabras de amor alternan con los mas inocentes chistes, donde todo en fin es vida, movimiento, animación. Los trages que predominan son de telas lijeras y colores claros, como lo requiere la estacion, pero aun no hemos visto el color de la hoja seca, cuero, etc., que son los que recomiendan las últimas modas de la capital del mundo civilizado y de color de rosa claro que tan buena armonía hace con el verde follage de los árboles (El Guanche... 18/07/1863: 2) (sic).

También se publicó una editorial de El Guanche, en el que se proponía arbolar y hacer productivos los terrenos del sur de la ciudad, o sea la zona de costa, tal y como se había hecho en el norte tras el aprovechamiento de las aguas del monte de Aguirre por medio de cañerías y la aclimatación de árboles de otras latitudes. Otro suelto de El Fénix, de 1864, se congratulaba de que el guarda del arbolado público llevara uniforme y reclamaba que fuera de gala para las noches de paseo en la Alameda (El Guanche... 19/11/1863: 1; El Fénix... 17/05/1864: 2).

Como vemos, la prensa tinerfeña se fue convirtiendo en un agente fiscalizador de la gestión del arbolado de la ciudad, y similar dirección tomó el periódico de la Sociedad Económica de Amigos del País de Santa Cruz de Tenerife, que, a finales de los años sesenta, se hizo eco de una propuesta del socio del colectivo, Tomás Monteverde, sobre el arbolado de los alrededores de la ciudad, con el fin de que fuera estudiada por Sabino Berthelot y Eladio Roca. La idea, que otros periódicos reproducirían más tarde, sugería embellecer el aspecto de alrededor de la urbe con especies como el tabaquero, la pitera, el taray o tarahal y árboles como el algarrobo, la higuera y el pino marítimo; e implicar a los socios del colectivo en la tarea, al ser propietarios de varios de aquellos terrenos, y al Ayuntamiento, con el propósito final de cubrir «[...] de verde las vertientes que miran hacia el puerto, [de manera que] otro seria [sic] el efecto que causaria [sic] entre la arboleda la blancura de Santa Cruz y de las casas de sus alrededores [...]» (El Amigo del País periódico de la Sociedad Económica de Santa Cruz de Tenerife 01/01/1868: 151-154, 183; El Mensajero de Canarias 01/05/1868: 1).

Con el transcurrir de los años, la prensa en general, y el Eco del Comercio en particular, fue publicando con frecuencia las bondades del arbolado, refiriéndose a la humedad que ofrecían, a sus frutos, a la industria que se generaba en torno a sus troncos y ramas, o por sus propiedades salubres, hasta afirmar que: 
la falta absoluta de arbolado perpetúa las enfermedades, y hace degenerar las razas. Los árboles suavizan la aspereza dé los vientos secos del Norte, enemigos mortales del delicado pulmón y de los nervios irritables; debilitan el furor de los vientos, templan el abrasador calor de los paises [sic] cálidos [...] en una palabra, neutralizan toda accion $[s i c]$ maléfica de la atmosfera y mantienen en ella aquel grado de humedad y de frescura, tan necesarias para la conservacion [sic] de la vida (Eco del Comercio 08/08/1868: 1; 12/08/1868: 1).

Pero uno de los grandes cambios en la cubierta vegetal de la ciudad llegó con el proyecto de urbanización que, en 1872, encargó la Sociedad de Edificaciones y Reformas Urbanas a Francisco Aguilar, en el que se incluyó la regularización de la plaza Weyler según las normas de decoro y ornato público, con el fin de encuadrar y delimitar la plaza con la edificación de manzanas. Hasta ese momento, el solar ocupado por la plaza era un terraplén irregular usado como campo de revista militar. En 1875, pasó a manos municipales y se reestructuró en una plaza regular con árboles que se convirtió, a finales del siglo xıx, «[...] en el espacio que realzaba el edificio de la Capitanía General, en la principal encrucijada de la población y en el elemento generador de la trama viaria de Santa Cruz» (González 2009: 193).

\section{Arbolado público y asociacionismo profesional}

Así llegamos a finales del siglo xix en el que, a partir de 1879, y tras el nacimiento de la Academia Médico Quirúrgica de Canarias (1880), con sede en Santa Cruz de Tenerife, se hacen asiduos los escritos de profesionales de las ciencias, especialmente médicos, sobre higienismo en general y la importancia del arbolado en particular. De aquella época datan los escritos del médico Juan Bethencourt Alfonso ${ }^{31}$ en la Revista de Canarias sobre la higiene en Santa Cruz de Tenerife (Revista de Canarias 23/02/1879: 81-82; 08/03/1879: 105-106, 264267); coincidiendo, además, con su adscripción a la Sociedad El Museo Canario como socio corresponsal de esta en la ciudad tinerfeña, hecho que seguramente condicionó parte de sus postulados al tener contacto directo con los médicos higienistas de la isla vecina.

En octubre de 1880, Tenerife fue visitada por el catedrático de Patología Médica en la Facultad de Medicina de París Sigismond François Jaccoud, con el objeto de identificar en el mundo los lugares que presentaran las condiciones favorables para recuperarse de las enfermedades del pecho. En su recorrido, y al abordar la Isla junto a otros destinos como Madeira, Argel y la costa de Marruecos, concluyó que sus condiciones eran óptimas para superar estas enfermedades, pero no así las condiciones higiénicas. En términos parecidos se expresaba el arquitecto Manuel de Cámara, insistiendo en las cuestiones que

31 Formado en la Universidad de Madrid, impulsó el Gabinete Científico en 1877, centro que desempeñó un papel clave en el estudio de la Historia Natural de las Islas y en el desarrollo de la antropología en Canarias. 
influían en la salubridad como la dirección, longitud y ancho de las calles; las dimensiones de las manzanas de las casas y su alto; la distribución y canalización de las aguas; $y$, como no, el arbolado (Castro 2012: 171-181).

Visto este desarrollo, no fue hasta 1881 cuando, de la mano del literato Patricio Estévanez y Murphy, se planteó por primera vez la creación de un parque municipal en Santa Cruz de Tenerife. La propuesta contó con el apoyo del citado Manuel de Cámara, con el favor de la prensa (que planteaba la construcción de un parque público inspirado en el Buen Retiro de Madrid) y con el impulso del médico Diego Guigou y Costa, que consideraba que el parque era fundamental como espacio higiénico para el desarrollo de la infancia, a través del juego como ejercicio saludable al aire libre ${ }^{32}$ (no nos detendremos en este asunto por escapar del marco temporal de nuestro objeto de estudio, pero es importante reseñar que, a pesar de los apoyos para la construcción del parque, el proyecto tuvo que esperar, aunque aquel movimiento primigenio sentó las bases para que, en 1926, se construyera el parque municipal García Sanabria, hoy declarado BIC, junto a sus bienes muebles, con la categoría de Jardín Histórico).

Los avances en materia de higienismo continuaron en las últimas décadas del siglo siendo de destacar el discurso que, en la sesión inaugural de los trabajos de la Academia Médico Quirúrgica en enero de 1882, pronunció el médico Antonio Soler sobre la importancia de la higiene (Revista de Canarias 23/02/1882: 38-41; 08/03/1882: 69-72), en el que proponía ahondar en la mejora de las condiciones higiénicas en el ámbito social y, en especial, en las viviendas (dándoles más luz, ventilación, saneando la atmósfera, mejorando la alimentación, etc.). Por otro lado, en agosto de 1883, vio la luz la publicación tinerfeña La Salud, revista quincenal de intereses vitales, que, dirigida por el licenciado en Medicina y Cirugía Miguel B. Espinosa, difundió trabajos de temáticas tan variadas como las aguas medicinales, la bondad de las variadas temperaturas y, cómo no, los beneficios higiénicos y sanitarios del arbolado. En esa línea se expresaba el artículo que, a los seis meses del nacimiento de la publicación, divulgó su director sobre los nacimientos, defunciones y enfermedades en Santa Cruz de Tenerife, achacando el bajo crecimiento poblacional en la urbe a problemas de higiene como «[...] las condiciones del aire atmosférico viciado por la falta casi total del arbolado público reducido casi exclusivamente á [sic] la plaza de La Libertad [...]» (Espinosa 1884: 194). Procurando hallar una solución al problema de la higiene en la ciudad, el médico municipal Agustín Pisaca, que estaba a la cabeza de la comisión de salubridad, dejó plasmada en su memoria de 1885, sobre La Higiene de la poblacion [sic] de Santa Cruz, un plan estratégico de saneamiento que no se llevó a cabo pero que pretendía eliminar las condiciones insalubres de la urbe. Dos años más tarde, el 2 de enero de 1887, Manuel de Cámara, por su parte, fundó la Sociedad de Higiene, un organismo que unió sus

32 Guigou y Costa, formado en la Universidad de Cádiz, fue el impulsor y primer director del Hospital infantil de Santa Cruz de Tenerife, inaugurado en 1901 y popularmente conocido como El Hospitalito (Betancor 2008: 1076-1078). 
esfuerzos a la comisión de salubridad para proponer planes de saneamiento, y que dio lugar, varias décadas más tarde, a un Comité de Saneamiento (R.O. de 29 de marzo de 1928), que velaría por la higiene del puerto y de la ciudad (Castro 2012: 181-182).

Y así llegamos al final del siglo XIx, en el que las investigaciones de Robert Koch y, sobre todo, de Louis Pasteur, descubrieron que las enfermedades se relacionaban con microorganismos y no con las emanaciones de las sustancias, por lo que la higiene pasó a ahondar en cuestiones como el análisis de las bacterias del agua, se recogían las basuras, se prohibían las fábricas en las zonas de vivienda, etc. Pero también se empezaron a tratar otros aspectos relacionados, de forma indirecta, con la enfermedad: los salarios, las condiciones laborales, el medio ambiente y las relaciones de los árboles con lo social-educativo. Este fue el contexto en el que surgió en España la Fiesta del Árbol, relacionada con los Árboles de la Libertad de la Independencia Americana y en especial con la Fiesta del Árbol de la Libertad de la Revolución Francesa, a raíz del impulso del ingeniero de montes Rafael Puig, que propagó la festividad desde Barcelona a otros territorios nacionales e internacionales (Sierra, 2011: 19-22, 32-45), y que también llegó a Canarias, siendo sus principales defensores en el Archipiélago: Francisco González Díaz (Naranjo 2009-2010), Manuel de Ossuna y van den Heede y Diego Guigou (García Martín 2012: 172; Quesada 1992: 1512-1513, 1517-1519), entre otros. No obstante, este es otro capítulo de la historia del verde urbano en las Islas.

\section{Conclusiones}

Las líneas desarrolladas a lo largo de estas páginas nos han permitido confirmar que, al igual que ocurrió en el resto del país, en las ciudades de Las Palmas de Gran Canaria y en Santa Cruz de Tenerife, desde el siglo xviII, y especialmente a partir de la segunda mitad del siglo XIX, el arbolado se fue incorporando al espacio urbano como elemento de decoro y moralidad, pero también por sus características higiénico-sanitarias. Hasta los años ochenta, los argumentos de la utilidad arbórea, en términos de salubridad, iban en la línea de sus cualidades para purificar el aire, controlar las temperaturas y atraer las lluvias, propios del período miasmático; pero, a partir de aquella década, con el desarrollo de la actividad portuaria, la expansión urbana, el crecimiento poblacional y el asociacionismo profesional, entre otros, estos razonamientos tendieron a un análisis posbacteriano, que, a su vez, desembocaría en un higienismo social en el que se reconocía en el árbol, aparte de los atributos mencionados, las bondades para la salud, en términos de mejora del estado físico y mental al estar en contacto con la naturaleza.

En materia de gestión, la responsabilidad del arbolado recayó en las instituciones municipales, pero fueron la prensa, el interés de particulares $\mathrm{y}$, especialmente, las iniciativas de profesionales (en ocasiones canalizadas a través de la sociedad civil) quienes adoptaron y difundieron en las Islas 
los postulados higienistas aplicados a la vegetación, aunque, en términos generales, nunca se dispuso de un plan en la materia. En el caso de los profesionales, eran fundamentalmente médicos que, formados en Francia o en las principales ciudades de la Península, como Madrid y Barcelona y Cádiz, ejercieron su profesión en las Islas y en ellas compartieron saber, experiencias e intereses, como la política y la historia natural, a través de los colectivos a los que pertenecían, como las Sociedades Económicas u otros centros culturales, científicos y profesionales (Museo Canario, Gabinete Literario, Gabinete Científico, Academia Médico Quirúrgica, etc.), dando lugar a una red de contactos y conocimientos entre las Islas y fuera de estas.

Este fue, en términos generales, el patrón común para las ciudades objeto de nuestro estudio, pero hemos podido detectar algunas particularidades y diferencias entre una y otra en el modo en que se fueron introduciendo los postulados higienistas en el arbolado público. Por un lado, aunque en ambas urbes la prensa desempeñó un papel fundamental como órgano de control de la gestión municipal arbórea y en la difusión del higienismo, hasta los años ochenta del siglo XIX, tuvo un rol de mayor relevancia en Santa Cruz de Tenerife; mientras que en Las Palmas de Gran Canaria fue un grupo de médicos, que giraba en torno a la figura de Domingo J. Navarro como precursor higienista y a la Sociedad Económica, quienes llevaron el timón en este sentido y, a partir de aquella década, el nacimiento de Sociedades semiprofesionales y academias especializadas ocasionó que estas tomaran especial protagonismo en el asunto. Y, por otro lado, mientras que en la ciudad de Las Palmas la preocupación por la mejora de la vegetación se concentró especialmente en la zona central de la urbe, frecuentada por la burguesía, en la de Santa Cruz de Tenerife se adoptó una mirada más amplia, en la que también se incluyó el entorno de la ciudad y algunos barrios. Es justo apuntar que, dada la amplitud del tema, se precisaría realizar un estudio más profundo para ahondar en estos supuestos, su influencia en el desarrollo del verde público urbano en las ciudades citadas y si se desarrollaron modelos extrapolables a la realidad del resto de núcleos urbanos del Archipiélago.

\section{Bibliografía}

Alcaide González R., 1999, «La introducción y el desarrollo del higienismo en España durante el siglo xix. Precursores, continuadores y marco legal de un proyecto científico y social», Scripta Nova revista electrónica de geografía $y$ ciencias sociales, n. ${ }^{\circ}$, p. 32-54.

Alzola J.M., 1961 [2008], Domingo Déniz Grek 1808-1877, Las Palmas de Gran Canaria, Fundación Mapfre Guanarteme.

Betancor Gómez M., 2008, «El papel de los parques en el desarrollo infantil para Diego Guigou y Costa (1861-1936)», XVII Coloquio de Historia Canario- 
Americana V Centenario de la muerte de Cristóbal Colón, Las Palmas de Gran Canaria, Cabildo Insular de Gran Canaria, p. 1071-1084.

Betancor Gómez M., [2014] 2016, «Profesionales de la salud en la segunda mitad del siglo XIX en Las Palmas», in Acosta Guerrero E. (coord.), XXI Coloquio de Historia Canario-Americana, Las Palmas de Gran Canaria, Cabildo de Gran Canaria, <http://coloquioscanariasamerica.casadecolon.com/index.php/ CHCA/issue/view/275>, consultado el 20/04/2020.

Bosch Millares J., 1967, Historia de la Medicina en Gran Canaria, Las Palmas, Cabildo Insular de Gran Canaria.

Castro Molina F., 2012, Arquitectura y medicina en Canarias. Dispositivos asistenciales $y$ recursos sanitarios en Tenerife ( $s . \mathrm{XVI-XX}$ ), tesis doctoral, Universidad de La Laguna.

Chesa Ponce N., 2020, Diccionario biográfico de médicos canarios nacidos durante el siglo XIX, Madrid, Mercurio editorial.

Del Caz Enjuto M., 2018, «Árboles urbanos: patrimonio natural y cultural para la construcción de ciudades civilizadas», Actas XI Congreso Internacional El papel del Patrimonio en la construcción de la Europa de los Ciudadanos, AR\&PA XI Bienal Ibérica del Patrimonio Cultural, Valladolid, Junta de Castilla y León, Consejería de Cultura y Turismo, p. 777-787.

Espinosa M., 1884, «Ojeada retrospectiva», La Salud revista quincenal de intereses vitales, n. ${ }^{\circ} 13$, p. 193-196.

García Martín M., 2012, Las ideas estéticas de Domingo Doreste (18681940), tesis doctoral, Universidad de La Laguna,<http://riull.ull.es/xmlui/ handle/915/9517>, consultado el 25/03/2020.

García Valencia, H., 05/12/2012, «El jardinero que fundó la Malva-rosa», Levante el Mercantil Valenciano.

González Chávez C., 1996, «La moderna arquitectura en el espacio urbano. Santa Cruz de Tenerife en el siglo XIX», Revista de Historia Canaria, n. ${ }^{\circ}$ 178, p. 83-92.

González Chávez C., 2009, «Urbanismo. Las ciudades canarias en el siglo XIX», in Hernández Gutiérrez S. y González Chávez C. M. (coord.), Arquitectura para la ciudad burguesa Canarias, Siglo XIX, Santa Cruz de Tenerife/Las Palmas de Gran Canaria, Gobierno de Canarias, «Historia cultural del arte en Canarias» p. 168-229.

González Lemus N., 2007, Clima y medicina: los orígenes del turismo en Canarias, Santa Cruz de Tenerife/Las Palmas de Gran Canaria, Ediciones Idea.

Herrera Piqué A., 2006, Pasión y aventura en la ciencia de las Luces, Las Palmas de Gran Canaria, Cabildo de Gran Canaria.

Martín del Castillo J., 2007, «Notas sobre la prevención sanitaria y el proyectismo higiénico a principios de siglo en Las Palmas de Gran Canaria», Boletín Millares Carló, n. ${ }^{\circ}$ 26, p. 59-68, <https://mdc.ulpgc.es/cdm/landingpage/ collection/bolmc $>$, consultado el 24/03/20. 
Naranjo Rodríguez R., 2009-2010, "Árboles, extraños en la ciudad», Rincones del Atlántico, n. ${ }^{\circ}$ 6-7, <https://www.rinconesdelatlantico.es/num6/lector. php?id=58>, consultado el 10/04/20.

Naranjo Santana M., 2016, Cultura, ciencia y sociabilidad en Las Palmas de Gran Canaria en el siglo XIX. El Gabinete Literario y El Museo Canario, Madrid, Mercurio editorial.

Navarro Pastrana D., Chil y Naranjo G., Suárez Pestana P., Rosa y Báez M., González y González M., Navarro Pérez L., Déniz Greck D., 1869, Análisis de las aguas de Azuaje en Gran Canaria, e informe médico sobre sus cualidades publicadas por la Sociedad de Amigos del País, Las Palmas de Gran Canaria, Sociedad Económica de Amigos del País de Las Palmas.

Navarro Pastrana D., 1895, Recuerdos de un noventón. Memorias de lo que fué la ciudad de Las Palmas de Gran Canaria á principios del siglo y de los usos y costumbres de sus habitantes, Las Palmas, Tip. La Verdad.

Navarro Pastrana D., 1896, Consejos de higiene pública a la ciudad de Las Palmas, Las Palmas, Tip. La Verdad.

Quesada Acosta A., 1990 [1992], «Ornamentación arbórea en la planificación urbana de Las Palmas de Gran Canaria durante el siglo XIX», IX Coloquio de Historia Canario-Americana, Las Palmas de Gran Canaria, Cabildo Insular de Gran Canaria, p. 1503-1529, <http://coloquioscanariasamerica.casadecolon. com/index.php/CHCA/issue/view/257>, consultado el 17/03/2020.

Regueira Benítez L., 11/02/2019, "Juan Padilla, fundador de El Museo Canario», La Provincia.

Reguera Rodríguez A., 1992, «Urbanismo y medioambiente en la España de la Ilustración. Estudio de varias problemáticas», Polígonos revista de Geografía, n. ${ }^{\circ}$ 2, p. 109-137.

Rodríguez Ocaña E. y Martínez Navarro F., 2008, Salud pública en España. De la Edad Media al siglo XxI, Andalucía, Consejería de Salud, Escuela Andaluza de Salud Pública.

Sierra Vigil J.M., 2011, La culta y simpática fiesta. La fiesta del árbol en la política forestal y la historia de España, Madrid, Gobierno de España, Ministerio de Medio ambiente y medio rural y marino.

Suárez Falcón J., s.f., Bocetos biográficos: D. Antonio López Botas, D. Antonio Artiles Ortega y D. Andrés Navarro Torrent, Las Palmas de Gran Canaria, Tipografía Lezcano.

Tous Meliá J., 2015, La medida del Teide: historia, descripciones, erupciones y cartografía, Tenerife, Juan Tous Meliá.

\section{Fuentes hemerográficas citadas}

Anales de la Sociedad Económica de Amigos del País de Las Palmas de Gran Canaria, 1871, 1873. 
Boletín de la Sociedad Económica de Amigos del País de Las Palmas de Gran Canaria, 1864, 1868.

El Amigo del País periódico de la Sociedad Económica de Santa Cruz de Tenerife, 1868.

El Canario: periódico de literatura, comercio, industria, noticias e intereses materiales, 1855.

El Eco del comercio, 1857-1859, 1861-1865, 1867-1868.

El Fénix, periódico semanal de literatura, artes, comercio y mejoras materiales, 1858-1859, 1863-1864.

El Guanche: periódico literario, científico, industrial, comercial y de intereses materiales, 1861-1864.

El Mensajero de Canarias periódico de anuncios comerciales, agrícolas e industriales, 1866, 1868.

El Ómnibus: periódico de noticias e intereses materiales, 1857, 1860, 1861, 1863, 1868.

El País: periódico local de intereses, 1865.

Revista de Canarias, 1879, 1882. 